\title{
GMR
}

\section{Genetic study of skin thickness and its association with postweaning growth in Nellore cattle: estimation of the genetic parameters}

\author{
A.M. Maiorano ${ }^{1}$, M.C.S. Oliveira ${ }^{2}$, J.N.S.G. Cyrillo³ ${ }^{3}$ L.G. Albuquerque ${ }^{1}$, \\ R.A. Curi ${ }^{4}$ and J.A.IIV. Silva ${ }^{4}$ \\ ${ }^{1}$ Faculdade de Ciências Agrárias e Veterinárias, \\ Universidade Estadual Paulista "Júlio de Mesquita Filho", Jaboticabal, SP, Brasil \\ ${ }^{2}$ Empresa Brasileira de Pesquisa Agropecuária, São Carlos, SP, Brasil \\ ${ }^{3}$ Instituto de Zootecnia, Sertãozinho, SP, Brasil \\ ${ }^{4}$ Faculdade de Medicina Veterinária e Zootecnia, \\ Universidade Estadual Paulista "Júlio de Mesquita Filho", Botucatu, SP, Brasil \\ Corresponding author: A.M. Maiorano \\ E-mail: amanda_maiorano@hotmail.com \\ Genet. Mol. Res. 15 (1): gmr.15017124 \\ Received July 1, 2015 \\ Accepted November 5, 2015 \\ Published February 19, 2016 \\ DOI http://dx.doi.org/10.4238/gmr.15017124
}

\begin{abstract}
The objective of the present study was to estimate genetic parameters for skin thickness (ST) and postweaning weight gain (PWG550) in Nellore cattle. Records were obtained from 152,392 Nellore animals born between 2001 and 2011. ST was measured in the posterior region of the animal's scapula with a millimeter caliper. The animals were assigned to different contemporary groups, formed on the basis of farm, year, sex, feeding regimen at weaning, date of weaning, feeding regimen at 450 days of age, and date of weighing at 450 days of age. The genetic parameters were estimated by Bayesian analysis using the GIBBS1F90 program. The mean ST and PWG550 observed were $7.71 \pm 2.04 \mathrm{~mm}$ and 115.95
\end{abstract}


$\pm 36.17 \mathrm{~kg}$, respectively. The posterior mean estimates of heritability $\left(\mathrm{h}^{2}\right)$ were $0.12 \pm 0.02$ and $0.29 \pm 0.02$ for ST and PWG550, respectively. The posterior mean estimates of the phenotypic, genetic, and environmental correlations between the traits were $0.16 \pm 0.0,0.17 \pm 0.02$, and $0.17 \pm 0.09$, respectively. The traits ST and PWG550 showed sufficient additive genetic variance to be used as selection criteria in breeding programs. The low genetic correlation obtained indicates that genes favoring the expression of one trait may not influence the other. Consequently, a selection favoring ST would be less efficient in increasing PWG550.

Key words: Skin thickness; Postweaning weight gain; Beef cattle; Bayesian analysis; Heritability; Genetic correlation

\section{INTRODUCTION}

Infestation with ticks presents a challenge to beef cattle production in tropical and subtropical regions, causing substantial economic losses as a consequence of transmitted diseases, limited weight gain, and death of the animals. The climate in Brazil favors the prevalence of a tick, Rhipicephalus microplus, which infests cattle throughout the country (Gonzales, 1993), and is the leading cause of economic losses in pasture-fed cattle (Parizi et al., 2009).

According to Mackinnon et al. (1991), a negative genetic correlation exists between the level of tick infestation and postweaning gain, with heavily infested animals causing losses in beef cattle production. Frisch et al. (2000) demonstrated that a parasite burden of 40 ticks/day would be associated with an annual reduction in weight gain by $10-15 \mathrm{~kg}$.

Genetic breeding for tick resistance in cattle may be effective in reducing the number of these parasites in the animal's body (Frisch et al., 2000; Budeli et al., 2009). Cattle have a large impact on the level of infestation with ticks (Wambura et al., 1998). Hence, the use of genetically resistant animals is an alternative to control ticks and to reduce production costs.

The magnitude of the heritability estimates for tick resistance and weight traits suggests that tick resistance could be increased at least as rapidly as growth in all or most cattle populations (Frisch et al., 2000). However, although selection for increased tick resistance is technically feasible in view of the heritability estimates, the method based on counting female ticks on one side of the animal's body (Wharton and Utech, 1970) is time-consuming and rarely used in commercial herds. It is, therefore, important to identify alternative and efficient traits that can be used for the selection of resistant cattle. In this context, there is evidence that the thickness of cattle skin influences tick resistance of the animal. Moreover, the relationship between skin thickness (ST) and weight gain should be studied in beef cattle since more heavily infested animals tend to gain less weight (Frisch et al., 2000).

The thickness of the skin is a physical barrier that impairs perforation by ticks (Carrera, 2013) and it is, therefore, believed that an increase in ST could increase the protection of the animal. According to Riek (1962), the areas of greatest larval fixation during the summers are those where the skin is thin, such as the flank, underarm, and dewlap. Thus, body areas of cattle with lesser ST may be preferential areas for the fixation of tick larvae.

To the best of our knowledge, there are no reports on the heritability estimates for ST in cattle. To use ST as a selection criterion in beef-breeding programs, it is necessary to estimate 
genetic parameters for this trait, as well as, to determine its genetic relationship with other traits of economic interest. Therefore, the objective of the present study was to estimate genetic parameters for ST and postweaning weight gain (PWG550) in Nellore cattle.

\section{MATERIAL AND METHODS}

Records of ST and PWG550 from 152,392 Nellore animals, born between 2001 and 2011, were used in the study. The database was obtained from the Nellore Qualitas Breeding Program, which employs selection for various traits. For this purpose, an empirical selection index was created in which all expected progeny differences (EPD) were standardized by the division of each EPD by the genetic standard deviation of the trait. The selection index of Nelore Qualitas considers $20 \%$ EPD for weaning weight, 40\% EPD for postweaning weight gain, 20\% EPD for scrotal circumference, and $20 \%$ EPD for muscularity at the yearling stage. Animals belonging to the Nelore Qualitas program were raised on a pasture-based feeding regimen, on farms in the States of São Paulo, Goiás, Mato Grosso, Mato Grosso do Sul, Tocantins, and Rondônia. The dataset from the program included weight records obtained since 1994 and records of ST obtained since 2001.

ST was measured at 450 days of age with a millimeter caliper in the region posterior to the scapula, immediately beyond the hump of the animal. According to Dowling (1955), the most widely used and accepted method to evaluate ST is skinfold measurement. The region posterior to the scapula is the best site to obtain this measurement in cattle since the skin is relatively uniform in this area (Tulloh, 1961). The measurement was done to identify the animals with thicker skin, which are considered by the program to be better adapted and more resistant to ticks. Postweaning weight gain was calculated as the difference between the adjusted weights at the age of 550 and 205 days.

The descriptive statistics of the variables and the dataset structure were obtained with the Statistical Analysis System program (SAS Institute, 2010). The general linear models procedure of the SAS program was used to define the non-genetic effects included in the statistical model used for the estimation of the genetic parameter.

The contemporary groups (CG) were defined by farm and year of birth, sex, feeding regimen at weaning, date of weaning, feeding regimen at 450 days of age, and date of weighing at 450 days of age. Only the data from animals older than 490 days and younger than 610 days were considered to maintain a maximum difference of 120 days between young and old animals. Poorly representative CGs with fewer than 10 animals, fewer than three sires, and records of animals with unknown parents were excluded. Moreover, records with a standard deviation of 3.5 above or below the mean CG were eliminated. The resulting database contained the records of 27,936 animals, offspring of 477 sires and 18,128 dams, distributed in 998 CG. The pedigree file included up to six generations, and 50,288 animals in the relationship matrix. The (co)variance components were estimated by Bayesian analysis using a multitrait model that included ST and PWG550. The analysis was performed using the GIBBS1F90 program (Misztal, 2014a) to obtain posterior estimates of the (co)variance components through sampling of conditional distributions using an iterative algorithm that permitted the estimation of marginal posterior distributions of the components (Resende et al., 2012).

The statistical model written in the matrix form was:

$$
Y=X b+Z a+e
$$

(Equation 1) 
where $y$ is the vector of the traits observed (ST, PWG550); $b$ is the vector of systematic effects; $a$ is the vector of random-additive genetic effects of the animal; $e$ is the vector of random-residual effects, and $X$ and $Z$ are the incidence matrices related to the systematic and additive genetic effects of the animal, respectively. It was assumed that the random-additive genetic effects of the animal and random-residual effects were independent and that and, thus obtaining, and, where is the additive genetic covariance matrix; is the residual covariance matrix; $A$ is the relationship matrix; I is the identity matrix of appropriate order; $N$ is the number of animals with records, and indicates the direct product between the matrices.

The a priori distributions of the effects included in the model were defined in the program settings. A non-informative a priori distribution was assumed for the systematic effects, with $p(b)$ constant. Inverse Wishart distributions were specified for the genetic and residual variances of the random effects, including co-variances (Van Tassell and Van Vleck, 1996). The initial inverse Wishart distributions for the (co)variance components were considered to be mutually independent. The posterior conditional distributions of the effects $b$, $a$, and $e$ were sampled from multivariate normal distributions.

A single chain of $1,100,000$ cycles was defined for Gibbs sampling, with a burn-in period of 100,000 cycles and a thinning interval of 20 cycles, which were established empirically.

Convergence of the results after Gibbs sampling was confirmed by graphic inspection, effective sample size, and the Geweke test (1992). The diagnosis of convergence based on the effective sample size uses the means and variances and is not useful for parameters that exhibit posterior distributions differing from the Gaussian distribution (Gelman et al., 2014). Since the marginal posterior densities of all (co)variance components approximated a normal distribution, the diagnosis based on effective sample size was expected to be efficient.

For both the traits, the posterior (co)variances were used to estimate the posterior measures of central tendency for heritabilities and correlations, as well as to obtain posterior standard deviations and $95 \%$ highest posterior density intervals.

\section{RESULTS}

The coefficients of variation observed for ST and PWG550 were of moderate to high magnitude (Table 1). For Nellore cattle populations, similar mean values for PWG550 (Table 1) have been reported previously in the literature (Boligon et al., 2011; Laureano et al., 2011).

Table 1. Descriptive statistics of skin thickness (ST) and postweaning weight gain (PWG550) in Nellore cattle.

\begin{tabular}{l|c|c|c|c|c}
\hline Trait & $\begin{array}{c}\text { No. of } \\
\text { observations }\end{array}$ & Measn \pm SD & Minimum value & $\begin{array}{c}\text { Maximum } \\
\text { value }\end{array}$ & CV $(\%)$ \\
\hline ST $(\mathrm{mm})$ & 17,940 & $7.71 \pm 2.04$ & 4.0 & 14.0 & 26.50 \\
\hline PWG550 $(\mathrm{kg})$ & 26,993 & $115.95 \pm 36.17$ & 8.0 & 227.0 & 31.19 \\
\hline
\end{tabular}

$\mathrm{SD}$, standard deviation; CV, coefficient of variation.

The trace plots of the posterior genetic components (Figure 1) and residual components (Figure 2) demonstrated convergence of the chains. The marginal posterior densities of heritability for ST and PWG550 (Figure 3) were obtained from the marginal posterior densities of the additive genetic and residual variances. As observed for the marginal posterior densities of all components (Figures 1 and 2), the marginal posterior densities of heritability exhibited symmetric measures of central tendency. The smallest effective sample size obtained in the study was 98 cycles and 
referred to the additive genetic and residual variance of PWG550 (Table 2). Geweke's convergence diagnostic (Table 2) was less than 1 for all the analyzed components, considering standard Z-scores to test the equality of log means of the conditional distribution of the first $10 \%$ and the last $50 \%$ of the samples.
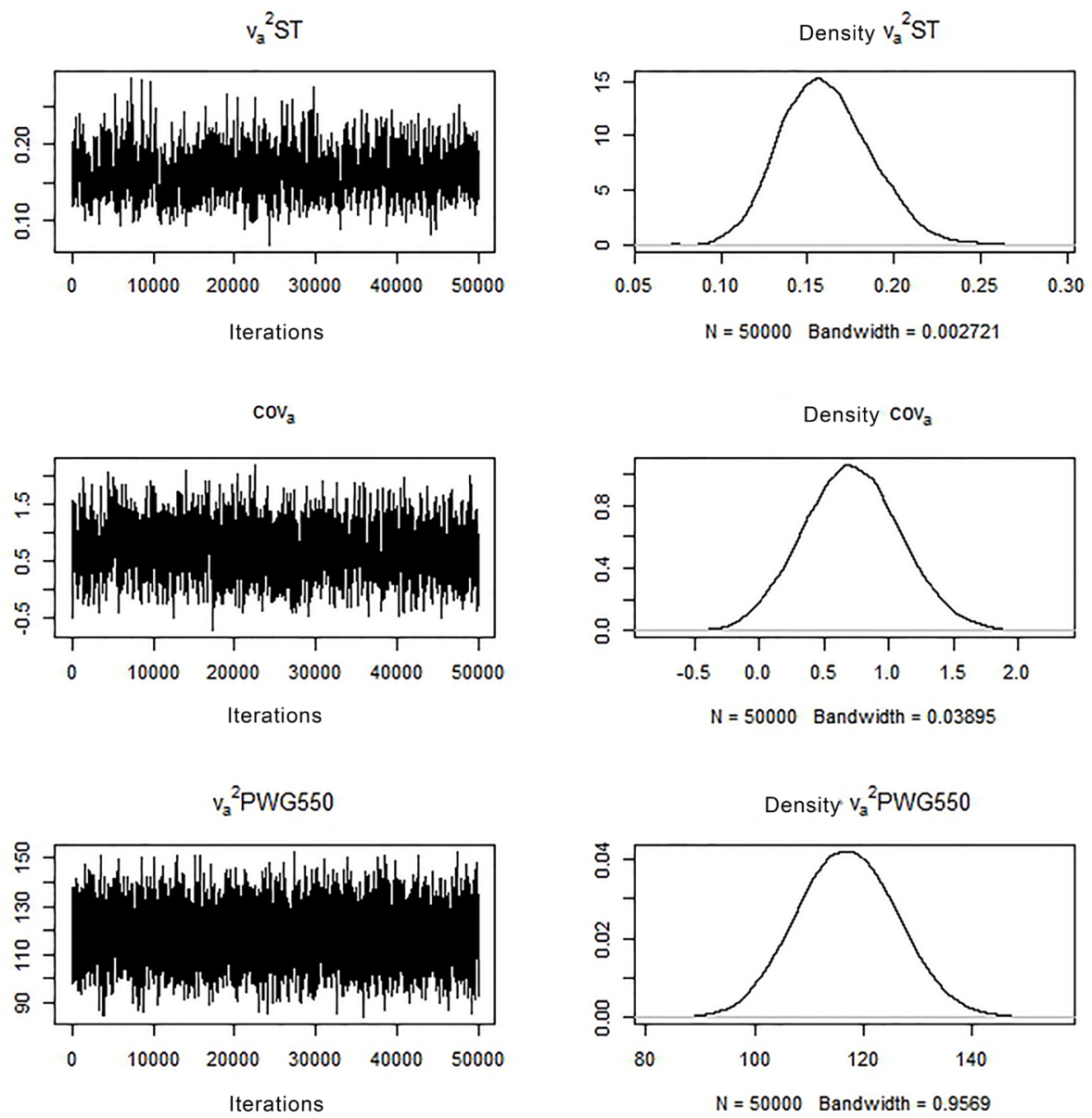

Figure 1. Trace plots and posterior density of the additive genetic variance $\left(\mathrm{v}_{\mathrm{a}}{ }^{2}\right)$ and additive covariance $\left(\operatorname{cov}_{\mathrm{a}}\right)$ components of skin thickness (ST) and postweaning weight gain (PWG550).

The results showed a higher additive genetic variance for PWG550 than for ST (Table 3). We found no studies in the literature reporting heritabilities of ST in cattle. This trait is of economic importance in sheep because it is associated with differences in wool production, and coefficients of heritability of 0.35 and $0.22-0.79$ have been reported by Slee et al. (1991) and Gregory (1982), respectively, for this trait.

The posterior mean estimates of the genetic, phenotypic, and environmental correlations demonstrated a low association between the traits studied (Table 3). 

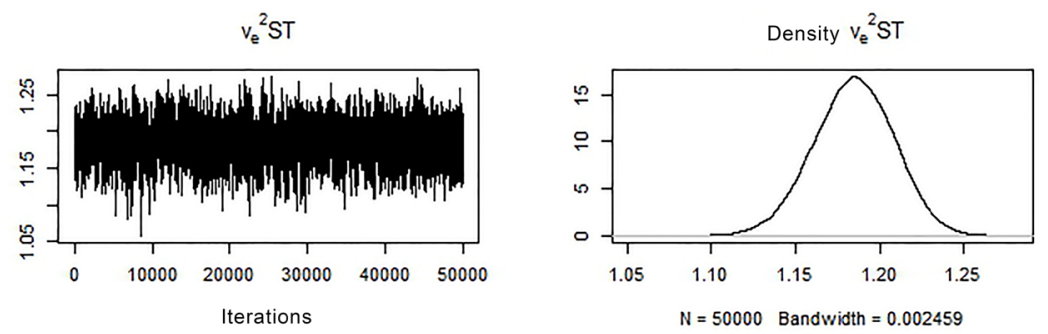

$\mathrm{cov}_{\mathrm{e}}$
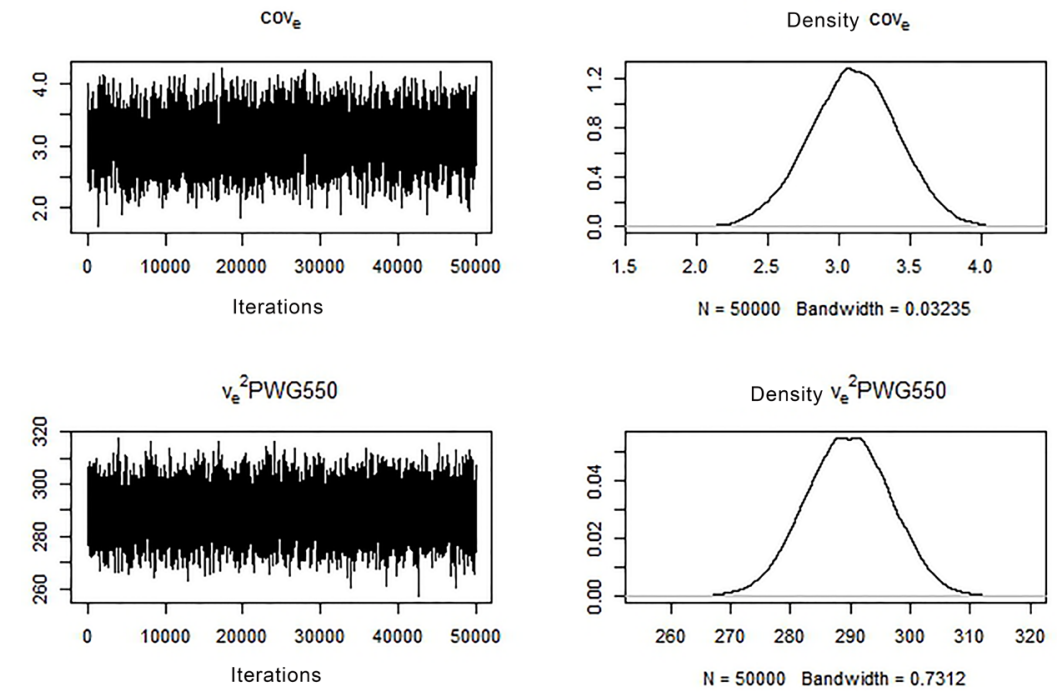

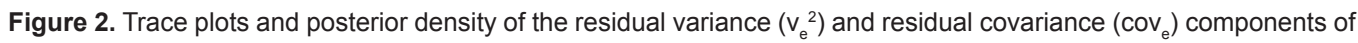
skin thickness (ST) and postweaning weight gain (PWG550).
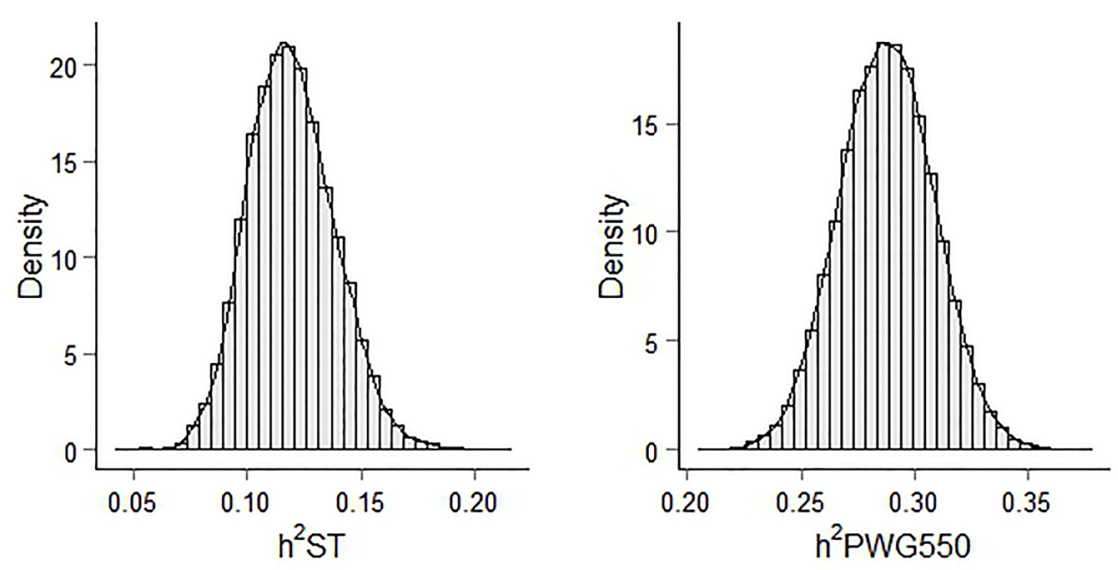

Figure 3. Marginal posterior densities of heritability $\left(\mathrm{h}^{2}\right)$ for skin thickness (ST) and postweaning weight gain (PWG550) obtained by two-trait Bayesian analysis. 
Table 2. Descriptive statistics of the posterior estimates of (co)variance components obtained by Bayesian analysis for skin thickness (ST) and postweaning weight gain (PWG550) in Nellore cattle.

\begin{tabular}{l|c|c|c|c|c|c}
\hline $\begin{array}{l}\text { (Co)variance } \\
\text { component }\end{array}$ & Mean & Median & Mode & $95 \%$ HPD & ESS & $\begin{array}{c}\text { Geweke } \\
\text { diagnostic }\end{array}$ \\
\hline $\mathrm{Va}^{2} \_\mathrm{ST}$ & $0.16 \pm 0.03$ & 0.16 & 0.16 & 0.11 to 0.21 & 406 & -0.02 \\
\hline $\mathrm{Ve}^{2} \_\mathrm{ST}$ & $1.18 \pm 0.02$ & 1.19 & 1.18 & 1.14 to 1.23 & 403 & 0.03 \\
\hline $\mathrm{Va}^{2} \_$PWG550 & $\begin{array}{c}117.06 \pm \\
9.25\end{array}$ & 117.00 & 114.87 & $\begin{array}{c}99.11 \text { to } \\
135.00\end{array}$ & 98 & 0.02 \\
\hline $\mathrm{Ve}^{2} \_$PWG550 & $\begin{array}{c}289.62 \pm \\
7.07\end{array}$ & 289.60 & 286.89 & $\begin{array}{c}275.80 \text { to } \\
303.30\end{array}$ & 98 & -0.02 \\
\hline CoVA & $0.72 \pm 0.38$ & 0.71 & 0.650 & -0.02 to 1.45 & 252 & 0.15 \\
\hline CoVe & $3.10 \pm 0.31$ & 3.10 & 3.05 & 2.48 to 3.71 & 222 & -0.14 \\
\hline
\end{tabular}

95\% HPD, 95\% highest posterior density intervals; ESS, effective sample size; $v_{a}^{2}$, additive genetic variance; $v_{\mathrm{e}}^{2}$, residual variance; $\operatorname{cov}_{\mathrm{A}}$, additive covariance; $\operatorname{cov}_{\mathrm{e}}$, residual covariance.

Table 3. Descriptive statistics of posterior estimates of the genetic parameters for skin thickness (ST) and postweaning weight gain (PWG550) in Nellore cattle obtained by two-trait Bayesian analysis.

\begin{tabular}{l|c|c|c|c}
\hline Parameter & Mean & Median & Mode & 95\% HPD \\
\hline $\mathrm{h}^{2} \_\mathrm{sT}$ & $0.12 \pm 0.02$ & 0.12 & 0.13 & 0.09 to 0.16 \\
\hline $\mathrm{h}^{2} \_$PWG550 & $0.29 \pm 0.02$ & 0.29 & 0.29 & 0.25 to 0.33 \\
\hline $\mathrm{ra}$ & $0.17 \pm 0.09$ & 0.17 & 0.24 & 0.00 to 0.34 \\
\hline $\mathrm{r}_{\mathrm{a}}$ & $0.17 \pm 0.02$ & 0.17 & 0.14 & 0.13 to 0.20 \\
\hline $\mathrm{r}_{\mathrm{f}}$ & $0.16 \pm 0.00$ & 0.16 & 0.17 & 0.14 to 0.18 \\
\hline
\end{tabular}

95\% HPD; 95\% highest posterior density intervals; $h^{2}$, posterior estimate of heritability; $r_{a}$, posterior estimate of genetic correlation; $r_{e}$, posterior estimate of environmental correlation; $r_{f}$, posterior estimate of phenotypic correlation.

\section{DISCUSSION}

The coefficients of variation obtained for ST and PWG550 suggest that, if the traits were subjected to selection, animals with extreme phenotypic values would exist to be evaluated as reproducers; in the case of ST, animals with genetic value for thin or thick skin could be chosen. According to Carrera (2013), the thicker the animal's skin, the more difficult is the access of ticks to blood. It is therefore expected that cattle with high ST values are more resistant to ticks.

Convergence of the chains (Figure 1) was verified based on the stationary phase of the chains, which revealed no need for a longer burn-in period, and based on the distribution of values of the chains, which showed no major variations with the progression of the cycles. The stationary nature of the chain was also confirmed by the symmetric measures of the central tendency of the estimated components (Table 2) and by visualization of the marginal posterior densities.

The number of effective samples was higher than 10 , the minimum effective sample size 
expected to reach convergence, as recommended by Misztal (2014b). The effective sample size of the (co)variance components indicates the number of independent samples with information equivalent to that present in the dependent sample (Sorensen et al., 1995). Thus, the effective sample sizes obtained in the present study indicate that the established chain $(1,100,000$ cycles) was sufficient to obtain the number of effective samples and convergence for all the (co)variance components.

According to the test proposed by Geweke (1992), there was no lack of convergence of the Gibbs sampler. The values shown in Table 2 were lower than 1, i.e., the difference between the first and last half was less than 1 , indicating a convergence of the estimates.

The criteria used to verify the convergence of Bayesian inference showed that the burn-in period of 100,000 cycles and the thinning interval of 20 cycles considered in the implementation of the Gibbs sampler were sufficient to obtain accurate parameters of dispersion of the posterior estimates of (co)variances. It can, thus, be inferred that the estimates obtained represent the marginal posterior distributions of the components.

According to the samples of posterior densities of the (co)variances, the measures of the central tendency such as mean, mode, and median of the marginal posterior densities of heritability were also similar, demonstrating symmetry. Bayesian procedures provide more accurate estimates than those obtained with frequentist approaches, and it is an advantage of these procedures that standard deviations and confidence intervals, as well as the marginal posterior densities, can be obtained (Resende et al., 2012).

Considering the heritability for ST found in the present study and those reported in the literature for other species, this trait shows sufficient additive genetic variance to be used as a selection criterion in animal-breeding programs. Although the posterior mean estimate of heritability for ST obtained in the population studied was low (Table 3), indicating slow genetic gain, the use of ST as a selection criterion should provide benefits and increase the number of animals with desirable genotypes.

The posterior estimate of heritability obtained for PWG550 was moderate. Laureano et al. (2011) estimated a lower heritability $(0.23)$ by the restricted maximum likelihood method. Using Bayesian analysis, Van Melis et al. (2010) and Boligon et al. (2012) reported heritabilities of 0.25 and 0.30 , respectively, for postweaning weight gain in the Nellore cattle. The posterior estimate of heritability obtained in the present study agrees with those reported by other authors for Nellore populations, suggesting that direct selection for this trait should result in genetic progress in the population.

The posterior mean estimate of the genetic correlation between ST and PWG550 was low (Table 3), indicating that the genes favoring the expression of one trait may not influence the expression of the other. However, since the correlation was positive, selection for one trait would not compromise the genetic gain in the other. If the objective is to obtain simultaneous genetic gain in both the traits, a weighted selection index should be created that places greater emphasis on postweaning weight gain.

The posterior mean estimate of the phenotypic correlation between ST and PWG550 suggests a low association between the variables, i.e., animals with higher ST values generally do not gain more weight during the postweaning phase. With respect to the environmental correlation, variations in the environment that possibly influenced weight gain in a favorable manner had little influence on ST. Correlation estimates between ST and weight traits are sparse in the literature and it would, therefore, be interesting to conduct further studies to analyze different datasets for obtaining comparative parameters. 
Generally, the non-genetic factors that affect postweaning weight gain are related to the calf sex, year, and season of birth (Silva et al., 2004) and herd and feeding regimen (Santos et al., 2012), as well as, good nutritional management and health of the herd. Considering the environmental correlation between ST and PWG550, the non-additive factors that influence PWG550 should not affect ST, suggesting that the differences in ST between animals may not be affected during the postweaning period.

The objective of the present study was to estimate the genetic parameters for ST, considering the lack of studies describing the variance components for this trait, and to evaluate its genetic, environmental, and phenotypic association with the postweaning weight gain, a trait of economic interest to beef cattle production. Considering the previous scientific evidence demonstrating the association of ST and tick resistance, it is necessary to decide whether the former should be included as a selection criterion in animal-breeding programs in order to improve the production rates of the herd. However, it should be emphasized that no strong genetic correlation between the ST and postweaning weight gain was observed in the present study. As a consequence, selection using ST as a criterion will be less efficient in obtaining progress in postweaning gain and would, therefore, not contribute in increasing the production rates of beef cattle herds.

\section{Conflicts of interest}

The authors declare no conflict of interest.

\section{ACKNOWLEDGMENTS}

Research supported by Conselho Nacional de Desenvolvimento Científico e Tecnológico. We thank the Nellore Qualitas Program, notably Émerson Guimarães Moraes and Leonardo Frederico Nishimoto Souza, for providing the database used in this study.

\section{REFERENCES}

Boligon AA, Baldi F and de Albuquerque LG (2011). Genetic parameters and relationships between growth traits and scrotal circumference measured at different ages in Nellore cattle. Genet. Mol. Biol. 34: 225-230. http://dx.doi.org/10.1590/ $\underline{\text { S1415-47572011005000004 }}$

Boligon AA, Baldi F and Albuquerque LG (2012). Genetic correlations between heifer subsequent rebreeding and age at first calving and growth traits in Nellore cattle by Bayesian inference. Genet. Mol. Res. 11: 4516-4524. http://dx.doi. org/10.4238/2012. October.17.2

Budeli MA, Nephawe KA, Norris D, Selapa NW, et al. (2009). Genetic parameter estimates for tick resistance in Bonsmara cattle. S. Afr. J. Anim. Sci. 39: 321-327.

Carrera JPB (2013). Parâmetros genéticos para resistência aos carrapatos, helmintos gastrointestinais e Eimeria spp. e perspectivas do uso de seleção em bovinos da raça Nelore. Master's thesis, Escola de Veterinária, UFMG, Belo Horizonte.

Dowling DF (1955). The thickness of cattle skin. Aust. J. Agric. Res. 6: 776-785. http://dx.doi.org/10.1071/AR9550776

Frisch JE, O'Neill CJ and Kelly MJ (2000). Using genetics to control cattle parasites-the Rockhampton experience. Int. J. Parasitol. 30: 253-264. http://dx.doi.org/10.1016/S0020-7519(00)00010-2

Gelman A, Carlin JB, Stern HS, Dunson DB, et al. (2014). Bayesian data analysis. 3rd edn. CRC Press, Boca Raton.

Geweke J (1992). Evaluating the accurary of sampling- based approaches to the calculation of posterior moments. In: Bayesian statistics 4 (Bernardo JM, Berger JO, Dawid AP and Smith AFM, eds.). Oxford University Press, New York, 625- 631.

Gonzales JC (1993). O controle do carrapato do boi. Edição do Autor, Porto Alegre, 80.

Gregory IP (1982). Genetic studies of South Australian merino sheep. 4. Genetic, phenotypic and environmental correlations between various wool and body traits. Aust. J. Agric. Res. 33: 363-373. http://dx.doi.org/10.1071/AR9820363 
Laureano MMM, Boligon AA, Costa RB, Forni S, et al. (2011). Estimativas de herdabilidade e tendências genéticas para características de crescimento e reprodutivas em bovinos da raça Nelore. Arq. Bras. Med. Vet. Zootec. 63: $143-152$. http://dx.doi.org/10.1590/S0102-09352011000100022

Mackinnon MJ, Meyer K and Hetzel DJS (1991). Genetic variation and covariation for growth, parasite resistance and heat tolerance in tropical cattle. Livest. Prod. Sci. 27: 105-122. http://dx.doi.org/10.1016/0301-6226(91)90090-D

Misztal I (2014a). Old page for BLUPF90 family of programs.

Misztal I (2014b). POSTGIBBSF90.

Parizi LF, Pohl PC, Masuda A and Vaz IdaS, Jr. (2009). New approaches toward anti-Rhipicephalus (Boophilus) microplus tick vaccine. Rev. Bras. Parasitol. Vet. 18: 1-7. http://dx.doi.org/10.4322/rbpv.01801001

Resende MDV, Silva FF, Lopes PS and Azevedo CF (2012). Seleção Genômica Ampla (GWS) via modelos mistros (REML/ BLUP), inferência bayesiana (MCMC), regressâo aleatória multivariada (RRM) e estatística espacial. Universidade Federal de Viçosa, Departamento de Estatística, Viçosa.

Riek RF (1962). Studies on the reactions of animals infested with ticks: VI. Resistance of cattle to infestation with the tick Boophilus microplus. Aust. J. Agric. Res. 13: 532-550. http://dx.doi.org/10.1071/AR9620532

Santos GCJ, Lopes FB, Marques EG, Silva MC, et al. (2012). Tendência genética para pesos padronizados aos 205 , 365 e 550 dias de idade de bovinos Nelore da região norte do Brasil. Acta Scientiarum 34: 97-101.

SAS Institute (2010). SAS online doc. Version 8. Cary.

Silva NAM, Aquino LH, Silva FF and Oliveira AIG (2004). Curvas de crescimento e influência de fatores não-genéticos sobre as taxas de crescimento de bovinos da raça nelore. Cienc. Agrotec. 28: 647-654. http://dx.doi.org/10.1590/S141370542004000300022

Slee J, Alexander G, Bradley LR, Jackson N, et al. (1991). Genetic aspects of cold resistance and related characters in newborn Merino lambs. Aust. J. Exp. Agric. 31: 175-182. http://dx.doi.org/10.1071/EA9910175

Sorensen DA, Andersen S, Gianola D and Korsgaard I (1995). Bayesian inference in threshold models using Gibbs sampling. Genet. Sel. Evol. 27: 229-249. http://dx.doi.org/10.1186/1297-9686-27-3-229

Tulloh NM (1961). Variations in the skin and skin-fold thickness of beef cattle. Aust. J. Agric. Res. 12: 992-1004. http://dx.doi. org/10.1071/AR9610992

Van Melis MH, Oliveira HN, Eler JP, Ferraz JBS, et al. (2010). Additive genetic relationship of longevity with fertility and production traits in Nellore cattle based on bivariate models. Genet. Mol. Res. 9: 176-187. http://dx.doi.org/10.4238/ vol9-1gmr710

Van Tassell CP and Van Vleck LD (1996). Multiple-trait Gibbs sampler for animal models: flexible programs for Bayesian and likelihood-based (co)variance component inference. J. Anim. Sci. 74: 2586-2597.

Wambura PN, Gwakisa PS, Silayo RS and Rugaimukamu EA (1998). Breed-associated resistance to tick infestation in Bos indicus and their crosses with Bos taurus. Vet. Parasitol. 77: 63-70.http://dx.doi.org/10.1016/S0304-4017(97)00229-X

Wharton RH and Utech KBW (1970). The Relation between Engorgement and Dropping of B. microplus (Canestrini) (Ixodidae) to the Assesment of Thick Numbers on Cattle. J. Aust. Entomol. Soc. 9: 171-182. http://dx.doi.org/10.1111/j.1440-6055.1970. tb00788.x 